Original Research Paper

\title{
Investigating the Role of Fly Ash and Silica Fume in the Cement Hydration Process
}

\author{
Lucas Suarez, Taher M. Abu-Lebdeh, Miguel Picornell and Sameer A. Hamoush \\ Department of Civil, Architectural and Environmental Engineering, \\ North Carolina A\&T State University, Greensboro, NC, USA
}

Article history

Received: 16-02-2016

Revised: 17-02-2016

Accepted: 22-02-2016

Corresponding Author:

Taher M. Abu-Lebdeh

Department of Civil, Architectural and Environmental Engineering,

North Carolina A\&T State

University, Greensboro, NC, USA

Email: taher@ncat.edu

\begin{abstract}
This research work investigates the effect of fly ash and silica fume on cement paste hydration. Percentages of each additive were selected to replace the cement by volume to be studied at five different ages using water curing and vacuum curing. These percentages were compared alongside a controlled cement paste without additives. Testing was carried out on 350 samples. Analysis methods utilized Fourier Transfer Infrared Spectroscopy (FTIR) to monitor the hydration with spectra, Scanning Electron Microscope (SEM) to generate images for regional analysis and MTS testing machine for compressive strength. Results demonstrated that silica fume replacement had the highest overall increase in the CSH and thus in the strength of the hardened cement paste that was cured by water curing. Replacement of fly ash exhibited the highest overall strength under vacuum curing. Also, FTIR and SEM testing showed an increase in the change of CSH area with age. SEM testing revealed the formation of pores, $\mathrm{CSH}$ and $\mathrm{CH}$ in images at all ages. The area of $\mathrm{CSH}$ grows most in early ages and diminishes over time. Although it was clear that the method of curing makes a difference in hydration, further research is needed on the method of vacuum sealing hardened cement paste.
\end{abstract}

Keywords: Fly Ash, Silica Fume, Cement Hydration, FTIR, SEM

\section{Introduction}

The hydration of cement paste is responsible for the development of essentially every engineering property of cement paste. Some properties include hardening, temperature rise and shrinkage which can lead to cracking. The addition of water to dry cement causes the tricalcium aluminate to react with the gypsum producing ettringite and heat. Then, the tricalcium silicate is hydrated to produce the Calcium Silicate Hydrates (CSH), lime and heat. Calcium Silicate Hydrate (CSH) is the main and most important constituent of cement paste. Its hydration forms most of the new solid phases that give hardened cement paste its strength. Hydration phases can be seen in Fig. 1 as a scanning electron microscope image, the topic will be discussed later in this study.

The re-use of supplemental cementitious materials like fly ash gives a new value to the product deemed waste. Although this may be true, the addition of this supplemental material is known to have adverse effects on the compressive strength of the cement. The replacement of cement with fly ash by percentage effects the properties, those being both the filler and dilution effects. Fly ash contains pozzolans, a siliceous material possessing cementitious properties and consumes $\mathrm{CH}$ in the pozzolanic reaction. Zhang (2000) found that less $\mathrm{CH}$ will decelerate the hydration reaction, best for the overall hydration of the specimen. The higher the fly ash as replacement percent, inversely the $\mathrm{CH}$ content is reduced (Zhang, 2000; Lam, 2000). On the other hand, silica fume additive contains pozzolans which are siliceous and aluminous material which have no cementitious properties. However it will react with calcium hydroxide once hydrated. A pozzolanic reaction between silica fume and lime formed during cement hydration does not occur during the early stages of hydration. However, the presence of silica fume slightly increases the rate of cement hydration during the first few hours of hydration. Of major significance is how silica fume affects the total heat of hydration and infers that the same is occurring to the initial hydration reactions. The calorimetric study indicated that the hydration was modified by the presence of silica fume. 


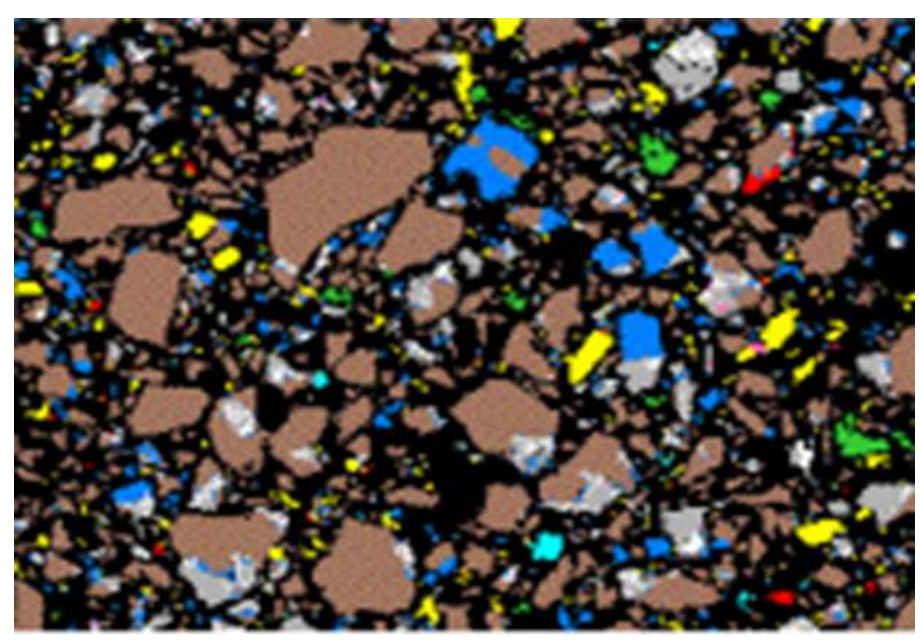

Fig. 1. SEM image with color coding based on hydration chemical phases (Artioli and Bullard, 2013)

The silica fume showed high activity in the early stages; and accelerated the hydration rate as compared to that of the reference cement paste. The fine silica fume particles provided nucleation sites for growth of hydrates. After silica fume hydrates grow both strength and the hydration heat increases and the pozzolanic activity takes over (Kadri and Duval, 2009).

The Hydrated Products include: Calcium Silicate Hydrate (CSH) which is the most critical hydration product as it fills the largest amount of space in hydrated cement and holds the microstructure together. $\mathrm{CSH}$ occupies approximately $50 \%$ of the paste volume and responsible to nearly all of the engineering properties of the cement paste. It forms a continuous layer which binds the cement particles into a cohesive solid on a nanometer level (Bullard, 2011). Calcium Hydroxide $(\mathrm{CH})$ occupies approximately $15 \%$ of the cement paste by volume. It forms as crystals within the cement paste that nucleate in the capillary pores and are large enough to be seen on an optical microscope. Calcium silicate hydrate and calcium hydroxide are both byproducts of the reaction of alite and water. Belite and alite are both minerals that react similarly with hydration (Kirby and Biernacki, 2012). Calcium aluminates and sulfoaluminate phases incorporate the hydration products which form the tricalcium aluminate and tetracalcium aluminoferrite minerals. They occupy approximately 15 to $25 \%$ by volume of the cement paste. They do not contribute as much to the engineering properties as of CSH in the cement paste. However, they cause the cement paste to undergo sulfate attacks which hinders the cement paste (Garcia-Mate, 2013).

The chemistry behind cement hydration is commonly studied using spectroscopic methods. This present work investigates the mechanical properties of cement paste as it goes under several stages of hydration, monitored by SEM and FTIR. FTIR can study both the crystalline and amorphous groups within cement paste. IR operates by utilizing groups of atoms on molecules which absorbs various wavelengths of infrared light, depending on the atoms corresponding to that specific molecule, immediate surroundings and its geometry (Ylmén, 2009). The objective of this work is to investigate the effect on cement hydration of supplemental fly ash or silica fume. The integration of these two additives were studied to analyze their effect in the growth of $\mathrm{CSH}$ with age. Percentages of each additive will replace the cement by volume at 5 and $10 \%$ to be studied at 3, 7, 14, 28 and 56 day ages. Testing will be carried out on 200 samples using Fourier Transfer Infrared Spectroscopy (FTIR) and Scanning Electron Microscope (SEM). The testing methods will portray the spectra and images of the samples. This study will provide an understanding and insight towards the roles of fly ash or silica fume in the hydration properties of cement paste at various stages of hydration.

\section{Experimental Program}

\section{Methodology}

This experimental study investigated the hydration of Portland cement with fly ash or silica fume compared to cement paste without the replacements. FTIR and SEM were used to monitor and portray the chemical transformations of the cement paste and MTS testing system was used to determine the compressive strength of the specimens at different ages and curing. Approximately 200 specimens were made using 4 in. by 8 in. cylinders and 150 specimens were made using 2 in. cubes. Half of the specimens were cured in water for 3, 7, 14, 28 and 56 days, while the other half were cured in vacuum for the same ages as water curing. Percentages of replacement of each additive were $0 \%$ (control specimen), 5 and $10 \%$ by volume of cement. Water cement ratio was kept constant at 0.4 as shown in the mix proportion in Table 1 . 


\section{Materials}

The cementitious materials used in this study were Portland cement, fly ash and silica fume. The cement is Type 1 Portland cement, manufactured by Lafarge Building Materials, INC. The fly ash material is Class F fly ash which has a good susceptibility to reducing the Alkali-Silica Reaction (ASR). It is a mixture of alumina, silica, unburned carbon and various metallic oxides. The main chemical components in fly ash is silicon dioxide $\left(\mathrm{SiO}_{2}\right)$, aluminum oxide $\left(\mathrm{Al}_{2} \mathrm{O}_{3}\right)$, iron oxide $\left(\mathrm{Fe}_{2} \mathrm{O}_{3}\right)$ and lime $(\mathrm{CaO})$. The silica fume is a very fine noncrystalline silica produced in electric arc furnaces as a byproduct of the production of elemental silicon or alloys containing silicon. Silicon dioxide makes up a large percentage of its chemical components. Chemical analysis of the cementitious materials is listed in Table 2 .

All materials were placed in a clean, labeled stainless steel mixing bowl and weighed to the nearest ten thousandth of a pound. The cement and fly ash or silica fume were measured and dry mixed together, the water was poured into the Hobart HL 200, 20 quart rotary mixer bowl. Then, the dry mixture (cement and additive) was added to the mixer bowl. Mixing starts at a low rate of 59 agitator rpm for $30 \mathrm{sec}$, followed by higher speed of 107 agitator rpm for one minute. After completing mixing, the mixture was carefully poured into cylinder molds. The cylinders were then rodded, vibrated and leveled before stored away for curing. Half of the specimens were cured in water, while the other half kept in seal vacuum curing until testing age.

\section{Specimens Preparation Process}

Once the desired testing age of 3, 7, 14, 28 and 56 days was reached, cylinders from each mix (water and vacuum cured) were cored using a Milwaukee Coring Rig Dymodrill, to extract a sample from the center. For coring, anchor down with two clinches, hook up hose, hook up extension cord, turn on water and drill and turn crank slowly to lower. After the entire length of the specimen is cored, label six lines for seven sections using a marker to mark a line at every inch. The samples received from the coring drill were taken to the SEM laboratories, where they were prep for SEM imaging. Within the SEM lab, a segment from each sample was cutout from the center of each cored sample using a diamond saw. These segments were approximately $3 / 4$ inches in diameter and $3 / 4$ inches in depth. The segments were properly labeled with the percentage of fly ash or silica fume, curing type and testing day and an arrow directing to the bottom surface used for imaging. Once cutout and labeled, the segments were placed into a small container with the arrow on the samples pointing downward. The samples were then epoxied using 33\% hardener and $66 \%$ resin. Right after the epoxy mixture was poured; the samples were placed into a vacuum pump and set to $27 \mathrm{kPa}$ until bubbles formed at the surface. The samples were left for approximately nine hours until the epoxy mixture harden. The segments were then sanded and polished using a MetaServ 250 grinder-polisher. With three pounds of force applied and at a constant 175 revolutions per minute, the samples were placed through five polishing pads. First, a two minute grind with 240 grit paper. Following, a four minute grind with 400 grit paper, an eight minute grind with 600 grit paper, a 12 min grind with 1200 grit paper and a 15 min polish of six micrometer grit paper using a six micrometer diamond polishing compound. All grinding also included ethylene glycol for lubrication. After wards, the samples were placed into a container filled with ethanol and sonicated for $10 \mathrm{~min}$ using the sonicator under the fume hood. The samples were then ready for microscopic examination. Figure 2 portrays the SEM sample preparation process.

Table 1. Mix proportion of the cement paste (lbs.)

\begin{tabular}{lcccrr}
\hline & Control & $5 \%$ F.A. & $10 \%$ F.A. & $5 \%$ S.F. & $10 \%$ S.F. \\
\hline Mix. No. & M1 & M2 & M3 & M4 & M5 \\
Cement & 24.0 & 24.00 & 24.00 & 0.00 & 24.00 \\
Fly Ash & 0.0 & 0.88 & 1.76 & 0.84 & 0.00 \\
Silica Fume & 0.0 & 0.00 & 10.30 & 9.94 & 1.68 \\
Water & 9.6 & 9.95 & 0.40 & 0.40 & 10.30 \\
w/c & 0.4 & 0.4 & & & 0.40 \\
\hline
\end{tabular}

Table 2. Chemical analysis of the cementitious materials

\begin{tabular}{lccc}
\hline $\mathrm{Chemical}$ & Portland cement (\%) & Fly Ash (\%) & Silica Fume (\%) \\
\hline $\mathrm{SiO}_{2}$ & 20.20 & 58.70 & 94.30 \\
$\mathrm{Al}_{2} \mathrm{O}_{3}$ & 4.80 & 31.40 & 1.10 \\
$\mathrm{CaO}$ & 64.30 & 0.73 & 0.49 \\
$\mathrm{MgO}$ & 1.20 & 0.70 & 0.87 \\
$\mathrm{Fe}_{2} \mathrm{O}_{3}$ & 3.20 & 3.70 & 0.70 \\
$\mathrm{Na}_{2} \mathrm{O}$ & 0.49 & 0.24 & 0.42 \\
$\mathrm{~K}_{2} \mathrm{O}$ & 0.31 & 0.92 & 1.32 \\
$\mathrm{SO}_{3}$ & 2.90 & 0.20 & - \\
\hline
\end{tabular}



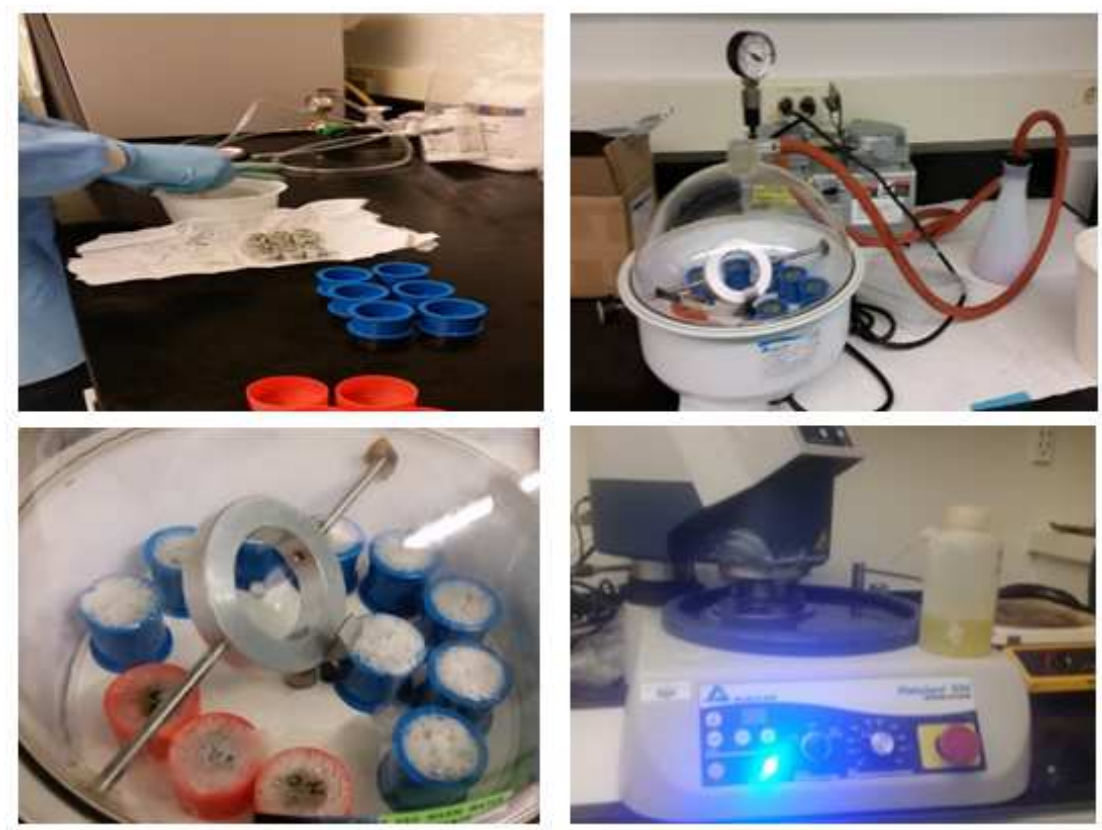

Fig. 2. Preparation of SEM samples

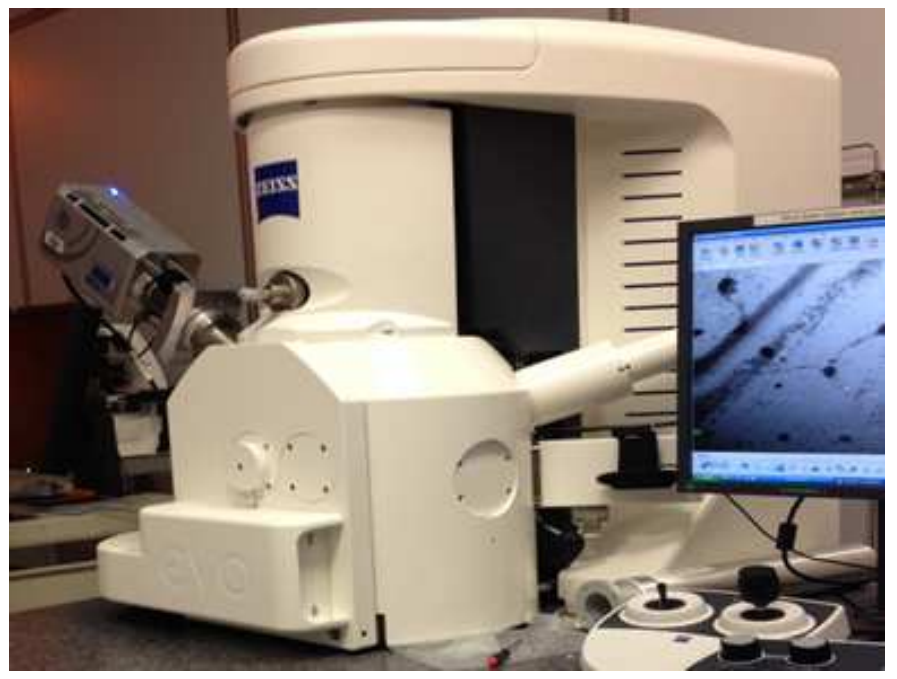

Fig. 3. SEM beam chamber and gun

\section{SEM Testing Procedures}

The samples were placed onto a sample holder using black carbon tape and positioned into the SEM. First, vent the chamber in the vacuum tab, slide in the sample holder holding all the samples (with the open channel flat surface on the bottom facing the flat surface on the SEM) so it is centered, calibrated and connects well. Second, set the Environmental Mode (EP) which allows atmosphere in the chamber since the sample is based on hydration. In the scanning tab, select a speed of four which will automatically change the scanning cycle time to $731 \mathrm{~ms}$. Verify the noise reduction is set to Line which integrates the lines of the image for a clearer scan. While the chamber pumps, hit the camera button on the keyboard to go ahead and get the first sample under the beam and place the sample under the cross hairs. Use the same center point technique in the stage navigation window to move the stage around for the processing of the next sample. Make certain that the tilt is on 0.0 degrees and the stage is calibrated. Figure 3 shows the SEM beam chamber and gun.

For the best resolution use a spot size greater than or equal to 500 but start at 500 to achieve a signal and progressively get smaller over time. Begin by looking for features like a uniformly gray area, bubbly rocks, 
calcium hydroxide which is smoother rocks with darker edges, tricalcium silicate is the fiber looking crystals and other hydrated product is in the gray area. A usual good starting point is setting the brightness to $50 \%$ and the contrast to $25 \%$. If there is not enough gray on the image, the contrast is too high so lower. The repetition is continued until the best balance of contrast and brightness is achieved. Open the histogram using the button on the bottom right after the scanning is complete to see if the adjusts are feasible.

For the Matlab analysis, a script is written in the editor to run the code that processes the images from the SEM. There are a total of five outputs from the Matlab script. The first is a figure of the original image of the sample. The second is a figure of the original image after it is analyzed with pixel color coding. The third is a histogram of the original image representing the pixel count of the level of gray. The fourth is a figure of a histogram of the original image with color coding divided into three distinct areas. The fifth are percentages of each of the areas compared to the complete histogram. The color coding is used to represent the five major hydration phases that are present in the image. These three phases are, from left to right, porosity, calcium silicate hydrate and calcium hydroxide. It should be noted that in the original image a Gaussian filter was selected for all analysis. In this filter there is a fixed standard deviation $(\sigma)$ value of 0.4 that represents an optimal grayscale which avoids noise vibrations in the image. Theses settings were selected for all image analysis.

\section{FTIR Testing Procedures}

Once the cube was crushed under compression, selected samples were collected and instantly analyzed with the FTIR machine. Prior to the sample placement onto the FTIR machine, the Omnic software was open to set-up the Experimental Setup. The program was set to collect and refresh data every 4 scans up to 8 scans. A background collection was collected prior to every sample being tested. The FTIR transform and subtraction of the background were performed automatically. A sample was then placed on top of the FTIR's diamond and pressed down by a device to prevent any space between the sample and diamond.

\section{Results}

\section{Compressive Strength}

The MTS 810 Landmark Servohydraulic Testing system was used to determine compressive strength of 2 in cube specimens cured in water and vacuum. Specimens tested were: Controlled $(0 \%), 5$ and $10 \%$ cement replacement by volume of fly ash and silica fume. Specimens were tested at 3, 7, 14, 28 and 56 days. Results for both water and vacuum curing are tabulated in Table 3 and 4 respectively. As shown, strength from 7 days to 56 days increased by $70,95,129$ and $82 \%$ due to incorporating 5 and $10 \%$ of fly ash and silica fume respectively. Compressive strength of the controlled specimen increased by $79 \%$ from 7 days to 56 days.

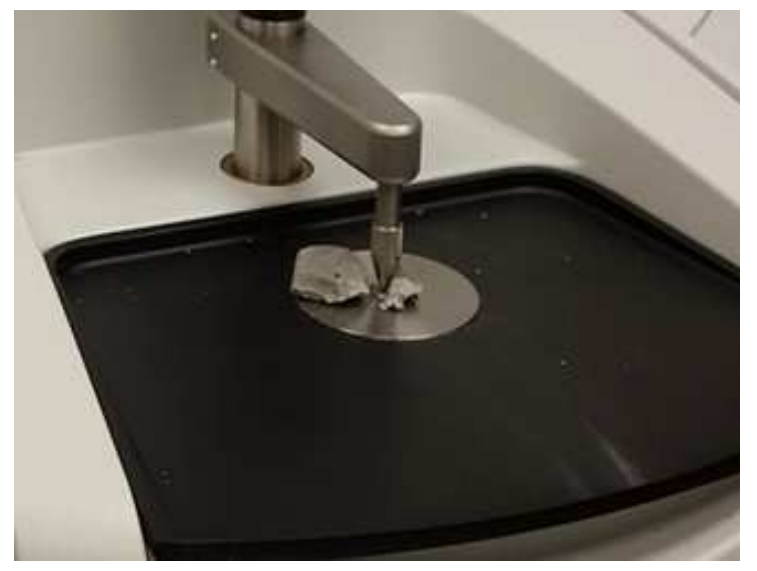

Fig. 4. Sample under FTIR testing

Table 3. Compressive strength-water cured specimens

\begin{tabular}{llllll}
\hline Replacement (\%) & 3 Day & 7 Day & 14 Day & 28 Day & 56 Day \\
\hline $0 \%$ & 5219 & 6058 & 7033 & 9505 & 10842 \\
$5 \%$ FA & 3973 & 7396 & 7462 & 10440 & 12511 \\
$10 \%$ FA & 4910 & 6567 & 7682 & 10936 & 12798 \\
$5 \%$ SF & 5197 & 5207 & 5649 & 10619 & 11920 \\
$10 \%$ SF & 5822 & 6231 & 6628 & 11329 \\
\hline
\end{tabular}

Table 4. Compressive strength-vacuum cured specimens

\begin{tabular}{llllll}
\hline Replacement \% & 3 Day & 7 Day & 14 Day & 28 Day & 56 Day \\
\hline $0 \%$ & 4838 & 5616 & 6056 & 7503 & 10508 \\
$5 \%$ FA & 3990 & 6652 & 7507 & 8967 & 11880 \\
$10 \%$ FA & 5931 & 5812 & 7929 & 9180 & 12166 \\
$5 \%$ SF & 4651 & 5124 & 5582 & 10998 \\
$10 \%$ SF & 5333 & 6250 & 6463 & 8545 & 10467 \\
\hline
\end{tabular}




\section{FTIR Results}

The first step in utilizing the FTIR is sample preparation. The samples analyzed in this study were fragments obtained from the crushing of the hardened cement paste, succeeding the compression tests. Each sample varied in size but was able to completely cover the diamond used for testing. Figure 4 shows a cement paste sample placed under the FTIR and ready for testing.

Before placing the specimen or sample onto the FTIR plate, a background check is performed to remove traces of dissolved gases and solvent molecules that can contribute information to the sample that does not exist within the sample. The background spectrum contains information about of the surrounding gasses and solvent molecules. This spectrum can then be subtracted away from the spectrum obtained from the sample tested. After the background has been collected, spectrum from the sample is then created, containing the absorption bands from that specific sample. For this experimental study, at least 5 spectrums were collected for each sample and the average of all the spectrums collected was recorded and used for results and discussion. After each sample spectrum has been obtained, data analysis was carried out and observed using the OMNIC software. For each sample, the absorption frequency bands assigned to each sample spectrum was observed for normal modes of vibrations within the molecules. These spectrums were later analyzed and compared.

Following the above steps, the hydration process was monitored for 3, 7, 14, 28 and 56 days, by acquiring an FTIR spectrum for each sample under water and vacuum curing. The recorded spectra for water and vacuum cured samples are displayed in Fig. 5 and 6 respectively. The curing days increase from 3 to 56 days, from bottom to top of the spectra. Calcium silicate hydrate is a weak bond structure which appears around $1100 \mathrm{~cm}^{-1}$ and can be associated with the peak in that region. To enhance these effects in the 900 to $1200 \mathrm{~cm}^{-1}$ region, serval difference spectra were created by subtracting the spectrum of the dry cement from the spectrums of the hydrated test samples. By using the dry cement spectrum as a reference, the spectroscopic features within the 900 to $1200 \mathrm{~cm}^{-1}$ region can be seen more clearly and can observe the development of $\mathrm{CSH}$ within this region.
The purpose of this subtraction technique is to remove the bonds of the reference material away from that of the sample material tested. This is performs by determining the difference in absorbance between the two spectra and plotting the difference against the wave number. When doing so, the reference spectrum is automatically multiplied by a subtraction factor so the reference materials bonds subtract out property (Pang, 2013). Figure 7 displays the results from the reference dry cement spectrum subtracted from the $0 \%$ control sample spectra for all testing days. The remaining difference spectra for all testing samples including fly ash and silica fume content and vacuum cured were collected but not shown.

Knowing that the formation of CSH occurs within the approximate region of 900 to $1100 \mathrm{~cm}^{-1}$, spectra can be zoomed into this area for further analysis. In Fig. 8 , the areas of the $0 \%$ control samples that were water cured, were calculated and shaded with the corresponding spectrum for all testing days. Knowing that the polymerization of silica to form CSH occurs within this approximate region, spectra can be zoomed in for further analysis. Using OMNIC software, the area of the peak region associated with $\mathrm{CSH}$ were exerted. Once obtaining the possible CSH formation from each sample, analysis were conducted and results are tabulated in Table 5.

\section{SEM Results}

The images in Fig. 9 and 10 illustrate the SEM images of the 28 day cement paste hydration under water cured control section at $1300 \mathrm{x}$ magnification without and with a filter, respectively. The filtered image has gone through both the convolution and median filters. The filter image has a great amount of details for the hydration products with the given area, whereas the original image is these hydration features are not as prominent.

Table 6 shows the water cured hydration phase as area percentages at all ages. The Table displays percentage of Calcium Silicate Hydrates (CSH), Calcium Hydroxide $(\mathrm{CH})$ and Porosity (P). As shown, the CSH areas of each material increase with age. Table 7 shows the vacuum cured hydration phase as area percentages at all ages. Again, the CSH areas of each material increase with age.

Table 5. Areas of CSH formation for all testing samples

\begin{tabular}{|c|c|c|c|c|c|c|c|c|}
\hline \multirow[b]{2}{*}{$(\%)$} & \multicolumn{4}{|c|}{ Water cured } & \multicolumn{4}{|c|}{ Vacuum cured } \\
\hline & 3 & 7 & 28 & 56 & 3 & 7 & 28 & 56 \\
\hline $0 \%$ & 8.80 & 8.96 & 9.57 & 12.6 & 9.90 & 10.20 & 11.20 & 11.90 \\
\hline $5 \% \mathrm{FA}$ & 10.10 & 10.20 & 10.60 & 10.4 & 5.69 & 9.81 & 10.60 & 11.20 \\
\hline $10 \% \mathrm{FA}$ & 8.73 & 10.60 & 12.30 & 12.7 & 11.30 & 11.80 & 12.80 & 13.30 \\
\hline $5 \% \mathrm{SF}$ & 10.10 & 10.50 & 11.00 & 11.3 & 116.00 & 12.30 & 12.50 & 12.60 \\
\hline $10 \% \mathrm{SF}$ & 11.70 & 12.30 & 12.60 & 14.0 & 11.89 & 12.04 & 13.63 & 14.18 \\
\hline
\end{tabular}




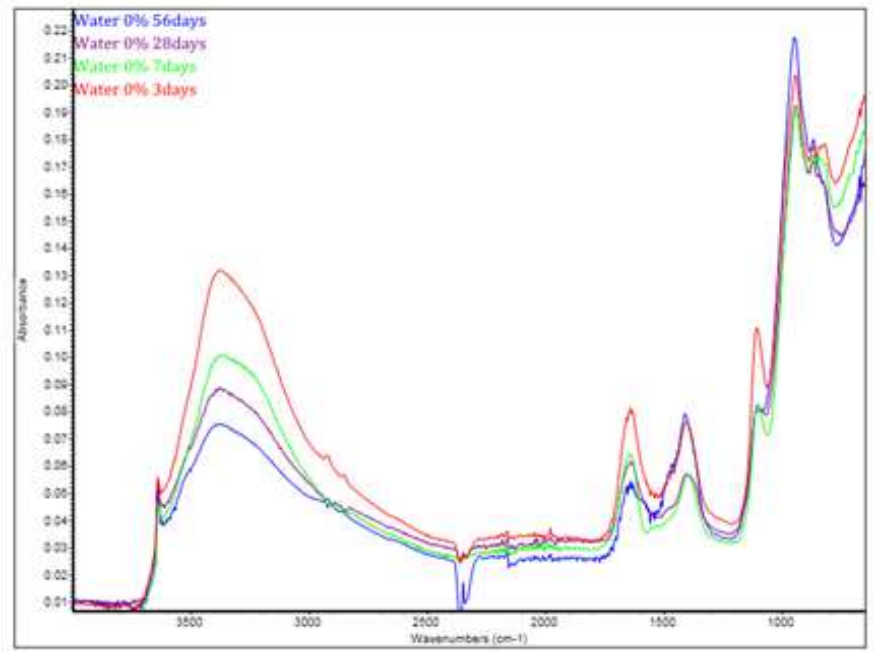

Fig. 5. Absorbance of $0 \%$ reference spectra of water cured samples, 3 to 56 day tests

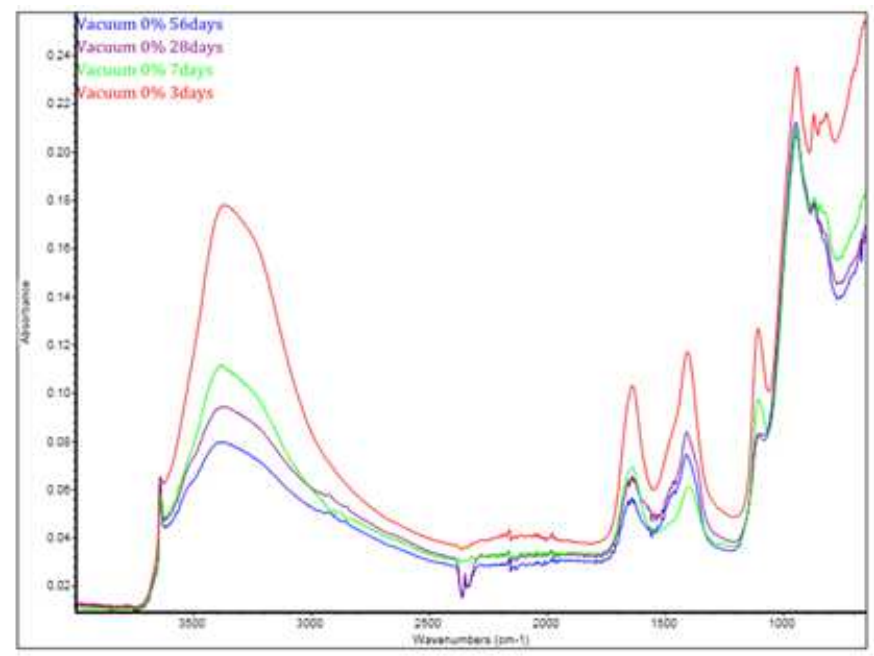

Fig. 6. Absorbance of $0 \%$ reference spectra of vacuum Cured samples, 3 to 56 day tests

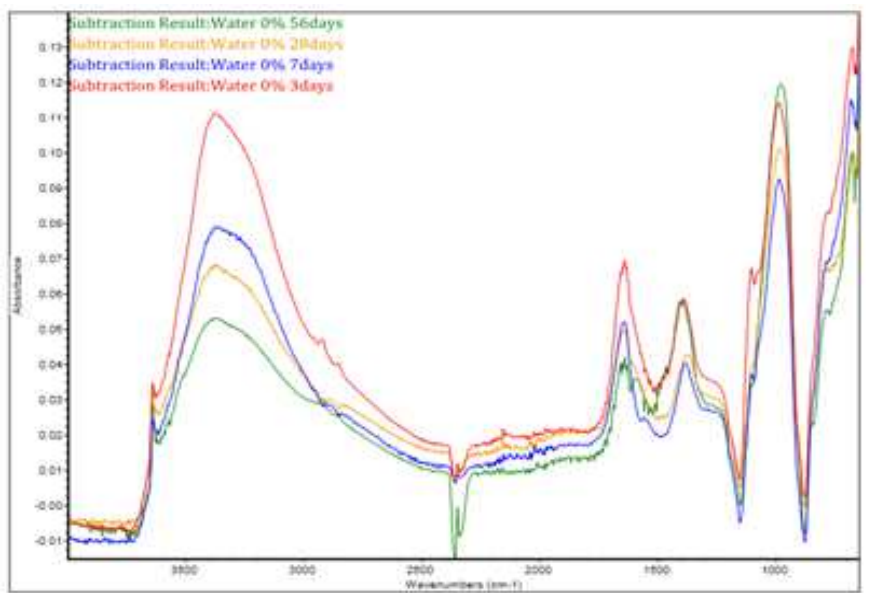

Fig. 7. Difference spectra of controlled water cured samples for all ages 


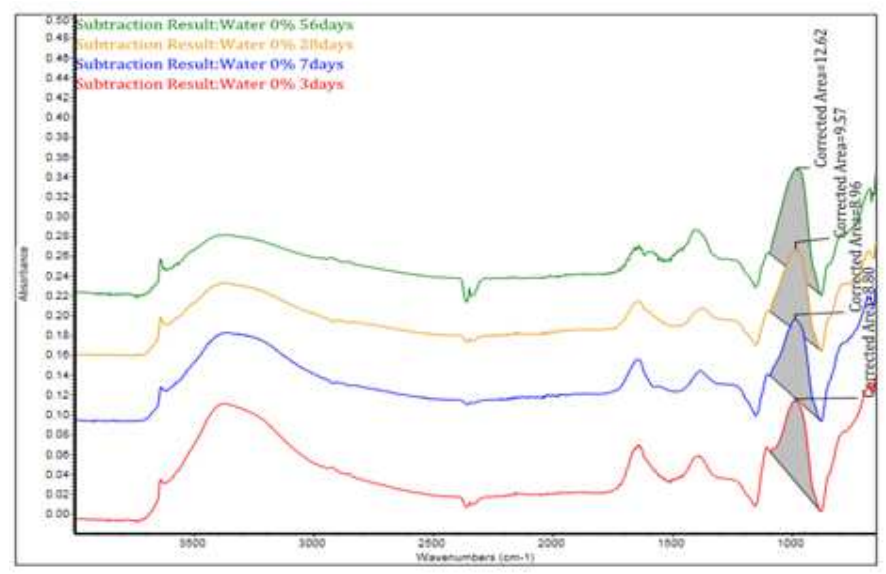

Fig. 8. Offset spectra of control water cured samples for all ages with CSH area

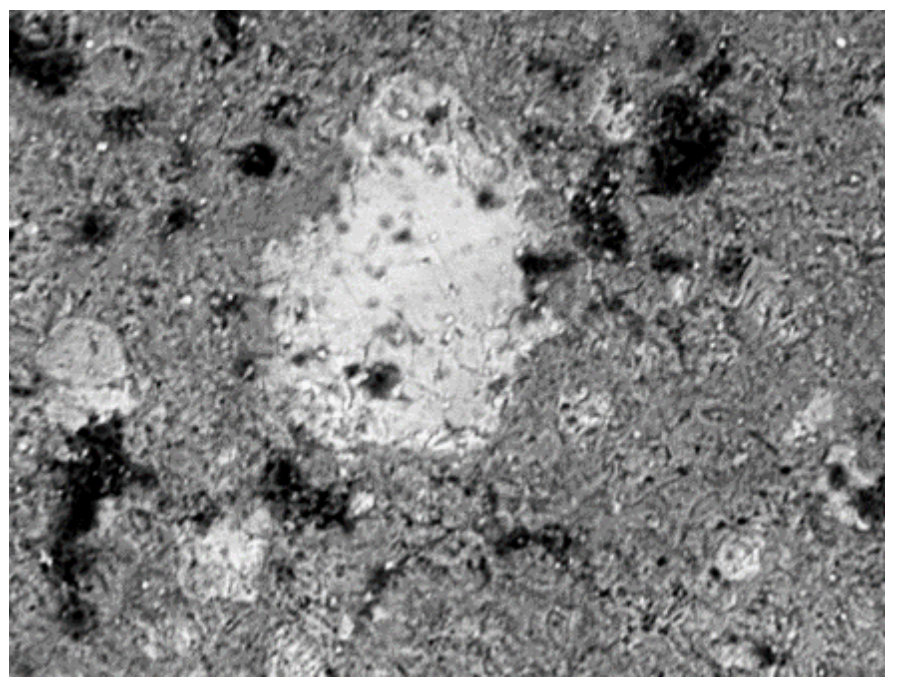

Fig. 9. SEM image of a 28 day water cured control section

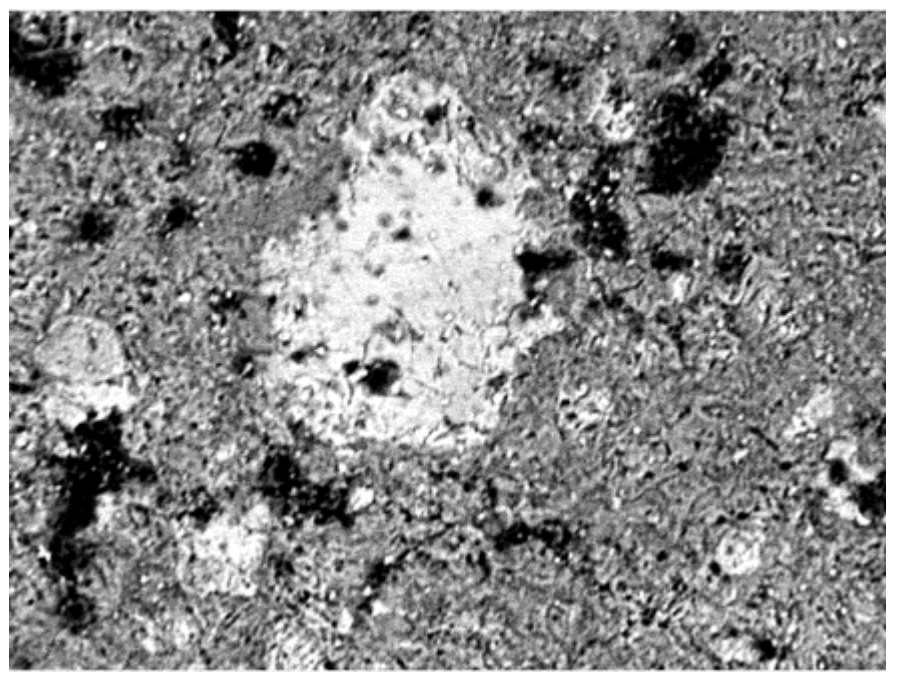

Fig. 10. Filtered SEM image of a 28 day water cured control section 


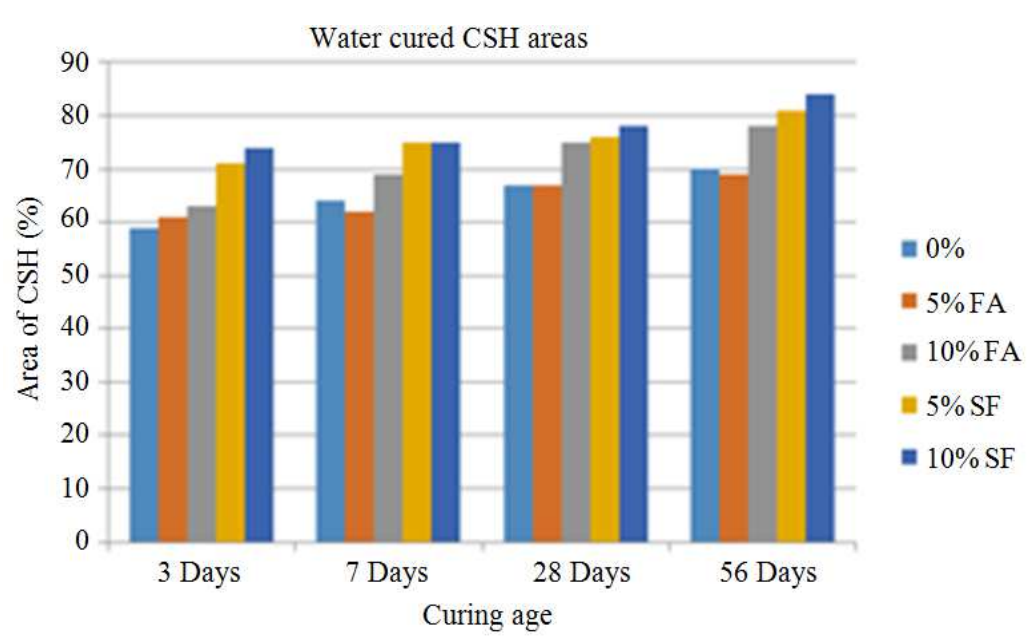

Fig. 11. CSH areas-water cured specimens

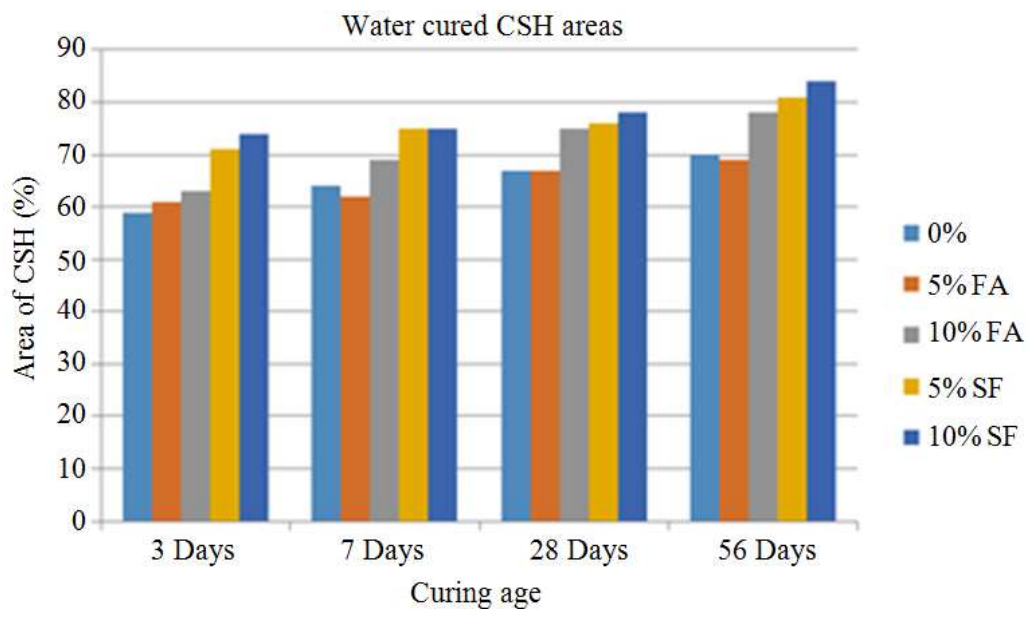

Fig. 12. CSH areas-vacuum cured specimens

Table 6. Hydration phase area percentages-water cured

\begin{tabular}{|c|c|c|c|c|c|c|}
\hline \multicolumn{7}{|c|}{ Water cure } \\
\hline \multirow[b]{2}{*}{ Days } & \multirow[b]{2}{*}{ Area } & \multirow{2}{*}{$\begin{array}{l}\text { Control } \\
0 \%\end{array}$} & \multicolumn{2}{|c|}{ Fly Ash } & \multicolumn{2}{|c|}{ Silica fume } \\
\hline & & & $5 \%$ & $10 \%$ & $5 \%$ & $10 \%$ \\
\hline \multirow[t]{3}{*}{3} & $\mathrm{P}$ & 17 & 14 & 27 & 18 & 20 \\
\hline & $\mathrm{CSH}$ & 59 & 61 & 63 & 71 & 74 \\
\hline & $\mathrm{CH}$ & 25 & 25 & 10 & 11 & 6 \\
\hline \multirow[t]{3}{*}{7} & $\mathrm{P}$ & 11 & 15 & 10 & 15 & 14 \\
\hline & $\mathrm{CSH}$ & 64 & 62 & 69 & 75 & 75 \\
\hline & $\mathrm{CH}$ & 25 & 22 & 22 & 10 & 11 \\
\hline \multirow[t]{3}{*}{14} & $\mathrm{P}$ & 14 & 13 & 18 & - & - \\
\hline & $\mathrm{CSH}$ & 66 & 65 & 73 & - & - \\
\hline & $\mathrm{CH}$ & 19 & 22 & 9 & - & - \\
\hline \multirow[t]{3}{*}{28} & $\mathrm{P}$ & 17 & 18 & 13 & 10 & 8 \\
\hline & $\mathrm{CSH}$ & 67 & 67 & 75 & 76 & 78 \\
\hline & $\mathrm{CH}$ & 17 & 14 & 12 & 14 & 14 \\
\hline \multirow[t]{3}{*}{56} & $\mathrm{P}$ & 10 & 14 & 14 & 9 & 7 \\
\hline & $\mathrm{CSH}$ & 70 & 69 & 78 & 81 & 84 \\
\hline & $\mathrm{CH}$ & 20 & 17 & 8 & 10 & 10 \\
\hline
\end{tabular}




\begin{tabular}{|c|c|c|c|c|c|c|}
\hline \multicolumn{7}{|c|}{ Vacuum cure } \\
\hline \multirow[b]{2}{*}{ Days } & \multirow[b]{2}{*}{ Area } & \multirow{2}{*}{$\begin{array}{l}\text { Control } \\
0 \% \\
\end{array}$} & \multicolumn{2}{|c|}{ Fly Ash } & \multicolumn{2}{|c|}{ Silica fume } \\
\hline & & & $5 \%$ & $10 \%$ & $5 \%$ & $10 \%$ \\
\hline \multirow[t]{3}{*}{3} & $\mathrm{P}$ & 19 & 19 & 18 & 23 & 15 \\
\hline & $\mathrm{CSH}$ & 61 & 60 & 64 & 67 & 75 \\
\hline & $\mathrm{CH}$ & 20 & 20 & 18 & 11 & 10 \\
\hline \multirow[t]{3}{*}{7} & $\mathrm{P}$ & 12 & 10 & 12 & 19 & 14 \\
\hline & $\mathrm{CSH}$ & 62 & 61 & 65 & 68 & 76 \\
\hline & $\mathrm{CH}$ & 26 & 29 & 22 & 13 & 10 \\
\hline \multirow[t]{3}{*}{14} & $\mathrm{P}$ & 17 & 15 & 5 & OUT & 17 \\
\hline & $\mathrm{CSH}$ & 67 & 62 & 69 & OUT & 77 \\
\hline & $\mathrm{CH}$ & 16 & 23 & 26 & OUT & 6 \\
\hline \multirow[t]{3}{*}{28} & $\mathrm{P}$ & 15 & 20 & 11 & 17 & 13 \\
\hline & $\mathrm{CSH}$ & 69 & 69 & 71 & 70 & 79 \\
\hline & $\mathrm{CH}$ & 16 & 11 & 18 & 13 & 8 \\
\hline \multirow[t]{3}{*}{56} & $\mathrm{P}$ & 16 & 13 & 11 & 6 & 5 \\
\hline & $\mathrm{CSH}$ & 70 & 70 & 72 & 70 & 80 \\
\hline & $\mathrm{CH}$ & 14 & 17 & 17 & 23 & 15 \\
\hline
\end{tabular}

Figure 11 and 12 illustrates the growth in CSH area with age for water and vacuum cured specimens respectively.

\section{Discussion}

\section{Compressive Strength}

The controlled specimens depicted a continuous increase in strength with age. In the case of the three days results, the reference specimens peaked at 5,219 psi for water cured and 4,838 psi for vacuum cured. The reference strength continued to increase with each age until to 56 day testing; in which the strength peaked at 10,842 and 10,508 psi for water and vacuum curing, respectively. The change in compressive strength for each additive in comparison to the control for water and vacuum cured show the largest margin of change for water cured samples of compressive strength is $22 \%$ in $5 \%$ fly ash at seven days. The smallest margin of change in water cured samples of compressive strength is $0 \%$ that occurs in $5 \%$ silica fume at 3 days. The largest change for vacuum cured samples of compressive strength is $34 \%$ in $10 \%$ fly ash at 28 days. The smallest change for vacuum cured samples of compressive strength is $0 \%$ that occurs in $10 \%$ fly ash at 56 days. Specimens with $10 \%$ fly ash outperformed in strength at all ages except for three day water cured results, in comparison to the control mix. The 3, 14, 28 and 56 day tests for the $10 \%$ fly ash water cured concretes, all performed higher than that of the $5 \%$ fly ash. On the other hand, after the addition of silica fume, the strength showed an increase in comparison to that of the reference specimen over time. Specimens with the addition of $10 \%$ of silica fume to cement replacement outperformed in strength at all ages except for three day water cured and 56 vacuum cured results, in comparison to the control mix. For all silica fume samples, 5\% displayed the highest stresses for 56 day tests. The stresses for the $5 \%$ silica fume replacement reached to 11,920 psi for the 56 day water cured samples. The $10 \%$ silica fume replacement samples obtained peaked stresses at 11,329 psi during the 56 day water cured tests. However, the 3, 7 and 14 day tests for the $10 \%$ silica fume water and vacuum cured concretes, all performed higher than that of the $5 \%$ silica fume concrete samples. At 3 and 28 days, the water cured 5 and $10 \%$ silica fume samples outperformed both fly ash replacements. The compression testing results indicate the optimum percentage of silica fume to cement replacement is that of the $5 \%$, due to its constant and higher stresses during most of all testing ages.

\section{Fourier Transform Infrared Spectroscopy (FTIR)}

The FTIR was used to monitor the hydration process of Portland cement with and without the addition of fly ash or silica fume over a course of 56 days for cement paste cured with the traditional water curing approach; in comparison to cement paste cured in vacuum environments. From the results, the areas of possible CSH formation have been determined for all cement paste samples tested. Results show an increase in $\mathrm{CSH}$ areas over time in the control, 5 and $10 \%$ fly ash and fume. At 56 days the $\mathrm{CSH}$ area was the largest for the silica fume with vacuum curing of $14 \%$. The largest CSH area for the fly ash occurred with $10 \%$ replacement vacuum curing at 56 days. The replacement of $5 \%$ fly ash water cured had the smallest 
change of area from three to 56 days, actually less than $1 \%$ change of area. The largest increase in CSH area from three days to 56 days was $5 \%$ fly ash vacuum cured with an increase of $5 \%$. The controlled cement paste was outperformed by both fly ash and silica in regards to change of $\mathrm{CSH}$ area over time. As a whole, the fly ash and silica fume both showed a strong a correlation for growing in $\mathrm{CSH}$ area with replacement percentage. The increase in the change in $\mathrm{CSH}$ area at 56 days for the $10 \%$ silica fume with water curing could be a result of additional hydration. The prolonged hydration is realized when internal pores filled with trapped water are reached by the growing $\mathrm{CSH}$ area during the later ages such as 56 days.

\section{Scanning Electron Microscope (SEM)}

In the original images and interpreted images are representations of the products of hydration. The formation of pores, $\mathrm{CSH}$ and $\mathrm{CH}$ is apparent in each image. The hydration has begun to occur in the very early stages such as the three day samples. During this age the hydration process is transporting at its most rapid. Hydration continues throughout the following 7-56 day durations. But it is progressively diminishing with age. Fewer pore spaces exist over time as the majority of space is filled with $\mathrm{CSH}$. The hydration will continue as long as water is present and there are still unhydrated compounds in the cement paste. Even though the CSH grows in the vacuum samples over time the curing method does not prove to be better than water curing. Variability in the seal of the bags lead to cracks in the vacuum samples which support the decrease in compressive strength over time.

\section{Conclusion}

In this study, the hydration process of Portland cement with fly ash or silica fume silica has been monitored. With the use of FTIR and SEM, signatures of CSH which produce most of the concretes' strength has been determined and examined from 3 to 56 days. From the results of this study, several conclusion have been drawn:

- The optimal percentage of cement replacement is that of the $5 \%$ silica fume, followed close by the $5 \%$ fly ash addition. $10 \%$ fly ash replacement results portrayed a decrease in strength in comparison to that of the $5 \%$ fly ash or silica fume additions

- Water curing proved to be the beneficial form of curing by displaying higher overall strength values than that of the vacuum cured method

- The appearance of an absorption peak between the approximate ranges of $875-1080 \mathrm{~cm}^{-1}$ was correlated with the formation of calcium silicate hydrate, $\mathrm{CSH}$. The area at which the possible formation of $\mathrm{CSH}$ was determined from each sample tested, has increased with respect to time; signifying the increase in strength over the course of testing days

- In all cases of replacement, the total area of CSH increased most for the 56 day FTIR test for both the water and vacuum cured samples. The largest decrease in normalized area from FTRI testing occurred for the vacuum cured $5 \%$ fly ash replacement. Increases in the change of CSH area in later ages could be due to prolonged hydration of the cement paste. The prolonged hydration is realized when internal pores filled with trapped water are reached by the growing $\mathrm{CSH}$ area

- Controlled cement paste water cured had $65 \%$ $\mathrm{CSH}$ average which was lower than fly ash and silica fume. Overall areas for water and vacuum curing have $\mathrm{CSH}$ percentages that continually grow larger with age for SEM. This trend aligns very well with the amount of $\mathrm{CSH}$ area growth for FTIR testing as well

\section{Acknowledgment}

This paper summarizes the findings of a research work supported in part by the National Science Foundation (NSF). Any findings, conclusions and recommendations expressed in this paper are those of the authors.

\section{Funding Information}

The work reported here was financially supported by the National Science Foundation (NSF).

\section{Author's Contributions}

Lucas Suarez: Participated in all experimental testing, data-analysis and contributed to the writing of the manuscript.

Taher M. Abu-Lebdeh: Participated in experimental plan and testing, data-analysis and contributed to the writing of the manuscript.

Miguel Picornell: Participated in experimental plan, data-analysis and contributed to the writing of the manuscript.

Sameer A. Hamoush: Participated in experimental plan, data-analysis and contributed to the writing of the manuscript.

\section{Ethics}

The authors would like to disclose that Dr. Taher M. Abu-Lebdeh (Co-author) is a member of the editorial board for the American Journal of Engineering and Applied Sciencs. 


\section{Reference}

Artioli, G. and J.W Bullard, 2013. Cement hydration: The role of adsorption and crystal growth. Crystal Res. Technol., 48: 903-918. DOI: $10.1002 /$ crat.201200713

Bullard, J.W., 2011. Mechanisms of cement hydration. Cement Concrete Res., 41: 1208-1223. DOI: 10.1016/j.cemconres.2010.09.011

Garcia-Mate, M., 2013. Hydration studies of calcium sulfoaluminate cements blended with fly ash. Cement Concrete Res., 54: 12-20. DOI: $10.1016 /$ j.cemconres.2013.07.010

Kadri, E. and R. Duval, 2009. Hydration heat kinetics of concrete with silica fume. Construct. Build. Mater., 23: 3388-3392.

DOI: $10.1016 /$ j.conbuildmat.2009.06.008

Kirby, D. and J. Biernacki, 2012. The effect of water-tocement ratio on the hydration kinetics of tricalcium silicate cements: Testing the two-step hydration hypothesis. Cement Concrete Res., 42: 1147-1156. DOI: 10.1016/j.cemconres.2012.05.009
Lam, L., 2000. Degree of hydration and gel/space ratio of high-volume fly ash/cement systems. Cement Concrete Res., 30: 747-756. DOI: 10.1016/S0008-8846(00)00213-1

Pang, X., 2013. A comparison study of Portland cement hydration kinetics as measured by chemical shrinkage and isothermal calorimetry. Cement Concrete Compos., 39: 23-32. DOI: 10.1016/j.cemconcomp.2013.03.007

Ylmén, R., 2009. Early hydration and setting of Portland cement monitored by IR, SEM and Vicat techniques. Cement Concrete Res., 39: 433-439. DOI: 10.1016/j.cemconres.2009.01.017

Zhang, Y.M., 2000. Hydration of high-volume fly ash cement paste. Cement Concrete Compos., 22: 445-452. DOI: $10.1016 / \mathrm{S} 0958-9465(00) 00044-5$ 